\title{
Recensão do livro Lisboa em Metamorfose ${ }^{1}$
}

Recensão

Sara Silva Lopes ${ }^{2}$

DINÂMIA'CET-Iscte, Portugal

O recente livro do geógrafo, professor e investigador João Seixas, intitulado Lisboa em Metamorfose - publicado em 2021 pela Fundação Francisco Manuel dos Santos -, expõe um ensaio reflectivo sobre os processos de transformação da cidade de Lisboa e da sua metrópole.

A óptica ensaísta transporta o leitor numa viagem pelo passado recente, presente e futuro próximo, bem como perspectiva a evolução e construção da cidade de Lisboa, com a ambição de responder "se a cidade é a mesma, ou não é a mesma? (Seixas, 2021b, p. 9) Como estão essas mudanças a ocorrer? E quais são os desafios que defronta a capital portuguesa?

Através de uma análise interpretativa, a cidade de Lisboa e a sua respectiva metrópole constituem-se enquanto casos de estudo individualizados das mudanças ocorridas nas grandes urbes. Estes territórios são utilizados como amostra das especificidades dos modelos urbanos globais implementados em diversas cidades de maior densidade.

Tais observações permitem não só ao autor a exploração das transformações das cidades, bem como possibilita aos leitores uma percepção ampla do crescimento, evolução e futuro da cidade de Lisboa.

Esta obra emerge de uma reflexão aberta e contínua sobre as temáticas relacionadas com a metamorfose deste território, articulando espaço urbano e economia, sociedade e cultura, bem como ecologia e política.

As reflexões contidas no estudo sobre as cidades contemporâneas e em particular sobre Lisboa, são matérias transversais às obras publicadas nos últimos anos pelo autor, nomeadamente "Projecções de Lisboa: Utopias e estratégias para uma cidade em movimento perpétuo" (2018) e "A cidade na encruzilhada: Repensar a cidade" (2013).

\section{Reflexões sobre os processos de transformação: Lisboa e sua Metrópole}

O livro abre com o prefácio, escrito pelo autor, que de entre diversos assuntos preambulares, explorados "de forma polifónica, numa sobreposição de diversas estruturas e escalas de composição" (Seixas, 2021b, p.7), são realçadas as questões de ordem global e das especificidades locais, associadas aos processos de transformação activos na cidade de Lisboa e sua metrópole.

Questões estas que serão expostas e discutidas ao longo do livro, em linha com posições de autores e estudos nacionais e internacionais, particularmente sobre as temáticas da crise do urbanismo e dos processos de metropolização.

\footnotetext{
${ }^{1}$ Seixas, J. (2021), Lisboa em Metamorfose, Lisboa: Fundação Francisco Manuel dos Santos, 170 pp.

2 sasls@iscte-iul.pt.
}

Copyright (C) 2021 (Silva Lopes, S.) Available at http://revistas.rcaap.pt/cct/
Licensed under the Creative Commons Attribution Non-commercial No Derivatives. DOI: $10.15847 /$ cct.26036
UIDB/03127/2020 
A estrutura desta obra divide-se em três partes e quinze capítulos, sendo precedidas pelo prefácio e sucedidas pela secção intitulada de 'Horizonte', que discute e perspectiva uma possível evolução da cidade num futuro próximo. No final do livro são incorporadas a selecção de referências bibliográficas e cinematográficas - para saber mais sobre a evolução contemporânea das cidades, incluindo o caso particular Lisboa - e os agradecimentos.

A primeira parte, intitulada de 'Lisboa', divide-se em quatro capítulos - 1) O Mediterrâneo e o Atlântico; 2) A pré-metrópole; 3) A grande urbe da Finisterra e 4) A Civitas de Lisboa - e aborda as constantes metamorfoses do território, bem como expõe as complexidades e dualidades que a constituem.

Com recurso ao livro Portugal, o Mediterrâneo e o Atlântico (1945), escrito pelo geógrafo e historiador Orlando Ribeiro (1911-1997), é narrada a condição da cidade de Lisboa como monocêntrica, com pequenas polaridades em redor, condição esta atribuída ao cariz mediterrâneo do território. Este cariz foi alterado nos últimos cinquenta anos, através de uma fragmentação do território ou 'explosão', como denomina o autor, que põe em causa esta característica monocentrísta.

O crescimento orgânico da cidade é especificado, desde o terramoto de 1755, passando pelo estabelecimentos dos limites administrativos da cidade em 1852, pelos Planos Gerais de Melhoramentos de 1864, pela nova visão da cidade planeada e integrada do engenheiro Duarte Pacheco (1900-1943) nas décadas de '30 e '40, pelo Plano Director de Lisboa de Étienne de Gröer (1882-1952) de 1948, até aos primeiros Planos de Urbanização que seguiram o princípio da Carta de Atenas, como os Bairros de Alvalade, Olivais e Chelas.

Apoiado na teoria de Oriol Nel·lo (1957) sobre o crescimento das grandes metrópoles contemporâneas, Seixas refere que "Lisboa é uma enorme «cidade dentro de cidades»" (Seixas, 2021b, p.24), conceito que utiliza para introduzir os fenómenos complexos de conurbação e metropolização da região urbana da Área Metropolitana de Lisboa (AML). Este conceito é explorado e discutido perante os padrões das actividades humanas, as estruturas morfológicas do território e as dinâmicas demográficas e económicas da metrópole de Lisboa, áreas emblemáticas na transformação sócio-territorial.

Sobre este assunto do desenvolvimento e crescimento da metrópole, importa recordar o artigo "Morfologias Urbanas e Espaços Públicos na Metrópole de Lisboa: Uma Aproximação Instrumental e Metodológica no Quadro de uma Investigação" (2002) - publicado na revista Cidades, Comunidades e Territórios, em co-autoria com o sociólogo e investigador Vítor Matias Ferreira (n-?) et al. - que expõe a investigação conduzida no âmbito do projecto "Património Urbano, Espaço Público e Protagonismo das Cidades: As Metrópoles de Lisboa e do Porto no Dealbar do Século XXI", sobre o protagonismo da metrópole de Lisboa no contexto do país e a importância dos seus espaços públicos como elementos condicionantes da configuração metropolitana.

Relativamente à dimensão territorial, sociocultural, económica e política das Civitas de Lisboa, são retomadas as reflexões teóricas de autores como Santo Agostinho (354-430), Friedrich Engels (1820-1895), Max Weber (18641920) e Richard Sennett (1943), com questões compreendidas entre as dicotomias das "interdependências entre a cidade de Deus e a cidade dos homens", das "tensões entre o progresso, habitat e segregação", da "dialética entre cidade, sociedade e política" e do "divórcio entre a ville (cidade física e urbanística) e a cité (cidade social e política)" (Seixas, 2021b, pp. 33 e 34; Seixas, 2021a), respectivamente.

A segunda parte, intitulada de 'Explosão', divide-se em quatro capítulos - 1) A metrópole triste e alegre; 2) A urbanização intensa; 3) O suburbano em qualificação e 4) O muito velho e o muito novo - e retrata a constante metamorfose na AML, a partir da sua caracterização urbana, social e política.

O livro Lisboa: Cidade triste e alegre, publicado em 1959 pelos arquitectos Vítor Palla (1922-2006) e Manuel Costa Martins (1922-1996), espelha a realidade da cidade de Lisboa e dos seus habitantes "à espera de melhores condições de vida [e] de algum tipo de progresso" (Seixas, 2021b, p. 44). Esta espera pelo progresso foi quebrada, no início dos anos 60, com a integração de Portugal no grupo de países que constituem a Associação Europeia de Comércio Livro (EFTA), que consequentemente transformou profundamente os tecidos industriais e produtivos do país. 
Este processo de transformação levou aos fenómenos das migrações dos anos 60 e 70, com milhares de pessoas as deslocarem-se para as áreas urbanas industriais da AML à procura de trabalho e melhores condições de vida. Este fenómeno exerceu forte pressão no território com a formação de novas centralidades e periferias (formação da Grande Lisboa) criadas através da construção de alojamentos, que geraram densificação do tecido urbano com recurso a bairros de habitação legal e informal (bairros de barracas e de génese ilegal) (Pinto \& Guerra, 2019; Salgueiro, 1977 e 1997) e que levaram à profunda alteração da paisagem das zonas rurais e periféricas e à explosão urbana da metrópole.

O conceito de explosão urbana, cunhado “por investigadores anglo-saxónicos nos anos '80 e 90', e utilizado pelos urbanistas Antonio Font, Franscesco Indovina e Nuno Portas numa exposição do Fórum Barcelona 2004 sobre as grandes transformações pós-industriais ocorridas nas principais metrópoles do Sul da Europa" (Seixas, 2021 b, p. 45), é o mote para a descrição da estrutura espacial urbana da AML, que sofreu de um desenvolvimento tardio, extenso e intenso (Pinto \& Guerra, 2019).

Com o crescimento e explosão urbana 'desordenada' do território, tornou-se essencial o reconhecimento "das questões urbanas para a coesão e o fomento do país” (Seixas, 2021b, p. 47), das políticas de urbanismo e do ordenamento do território como instrumento, apesar das insuficientes condições para uma gestão integrada do desenvolvimento da cidade e da sua metrópole. Em linha com o crescimento urbano 'desordenado', as desigualdades sócio-espaciais no sistema metropolitano acentuaram-se e desenharam a "condição urbana na sociedade portuguesa entre os anos 60 e os anos 80" (Drago, 2019, p. 10).

Perante tamanhas adversidades urbanas, sociais, económicas e políticas, a expansão metropolitana avança a uma velocidade intensa. A partir do núcleo central, com configuração radial, estendem-se cinco eixos de explosão determinados pela mobilidade rodoviária e ferroviária. Assim, as grandes infra-estruturas e equipamentos passam as ser os elementos agregadores e impulsionadores das urbanizações, a par das estruturas de mobilidade e alojamento.

A 'produção de espaço', após a explosão urbana fruto das profundas alterações demográficas, torna-se uma questão central e o motor do desenvolvimento. A procura por novos conceitos que acompanham as transformações e o crescimento abrupto das cidades, como por exemplo "a cidade difusa, a meta-polis, a hiper-cidade" (Seixas, 2021b, p. 60) são demonstrações de tentativas de configuração teórica ou até sócio-territorial de modelos urbanos de grandes metrópoles ou nas palavras de Oriol Nel·lo "grandes confins da cidade sem confins" (Seixas, 2021b, p. 61).

A restruturação económica da metrópole pós-industrial refletiu-se no território, particularmente nos locais suburbanos, que se tornaram territórios de eleição para a instalação de novas actividades económicas. A Grande Lisboa Central, como denominada por João Ferrão e Francisco Vala, numa análise realizada em 2001 sobre a delimitação e organização interna das principais aglomerações metropolitanas de Lisboa e Porto, é constituída por uma densa conurbação de manchas de contínuos construídos e três conjuntos de aglomerações urbanas de grande dimensão, localizadas nas margens norte e sul do estuário do Tejo. Em conjunto, estas três aglomerações têm cerca de dois terços dos residentes da AML.

Este é um território metropolitano com clara tendência de fragmentação urbana, "onde coexistem realidades contrastantes em áreas muito próximas, quer nas malhas mais centrais quer sobretudo nos grandes eixos radiais e de expansão urbana" (Seixas, 2021b, p. 66).

Os territórios suburbanos fragmentados, da década de '90, que se desenvolveram sobretudo nos municípios da Amadora, Odivelas e Loures - margem norte do rio Tejo - e Almada, Barreiro e Seixal - margem sul do rio Tejo - são amplamente criticados, devido à sua desqualificação e precarização. À semelhança de momentos anteriores, as infra-estruturas e os modos de transporte/mobilidade - Ponte sobre o Tejo, linha ferroviária de Sintra e IC-19, linha ferroviária de Cascais e autoestrada A5, Calçada de Carriche, linha ferroviária da Azambuja, Estrada Nacional 10 e autoestrada A1 e ponte Vasco da Gama - são estruturais na configuração e na qualificação destes sistemas urbanos. 
A aposta da construção das periferias em detrimento da regeneração e colmatação dos centros históricos, levou ao esvaziamento e à degradação dos mesmos, bem como a uma situação de continuidade do estigma sócio-espacial, que levantou questões de ordem urbana.

A 'questão urbana', trazida na década de '90 para os debates teóricos, "tornou-se central para as grandes questões da humanidade" (Seixas, 2021a). Foram as exigências urbanas da Europa Comunitária e das políticas de coesão que impulsionaram um pensamento sobre as cidades mais estruturado e debruçado sobre o tratamento das 'questões urbanas', tendo culminado na obrigatoriedade da existência de instrumentos de Planeamento Urbano e de Ordenamento do Território, nomeadamente dos Planos Directores Municipais.

A terceira parte, intitulada de 'Transição', divide-se em sete capítulos - 1) O bypass de Lisboa; 2) Economia em digitalização; 3) Disparidades e desigualdades; 4) Habitats em implosão; 5) Ecologia em regeneração; 6) A pósmetrópole e 7) A transcrição da Civitas de Lisboa - e discute os modelos urbanos e as suas transformações mais recentes, nomeadamente as de ordem global.

As sucessivas crises financeiras e sócio-urbanísticas, instaladas desde o ano de 2008 e 2009, empurraram a cidade de Lisboa a desenvolver a "Carta Estratégica" - apoiada em seis pilares fundamentais, que sugerem novas perspectivas de qualidade de vida e de governação da cidade e da metrópole - e a debruçar-se sobre os modelos europeus de desenvolvimento urbano, resultantes do relatório Cities of tomorrow.

Na segunda década do século XXI os modelos urbanos, de progresso social e económicos alteram-se para integrar uma ampla recuperação baseada em princípios ecológicos e tecnológicos. Este foi e é um tempo de transição, mais do que de mudança. Um tempo em que, segundo o autor "as trajetórias, interpretações e regulações da maioria destas mudanças são tanto conduzidas por agentes e factores de inovação, como por lógicas, estruturas e poderes pré-estabelecidos" (Seixas, 2021b, p. 83).

Lisboa encontra-se geográfica e politicamente num ponto estratégico. É uma das capitais da União Europeia que mantêm relacionamentos com os Países de Língua Oficial Portuguesa (PALOP), afirmando-se assim como um país de charneira, que se apresenta politicamente estável e com uma imagem notável internacionalmente. Contudo, também apresenta um relevante conjunto de fragilidades, nomeadamente nas áreas tecnológicas, económicas, produtivas e demográficas.

Acompanhando as tendências de outras capitais europeias, Lisboa aposta em novas políticas urbanas como a reabilitação urbana, a requalificação de espaços públicos, a construção de equipamentos, a acção social, o empreendedorismo económico e a sustentabilidade ambiental, ainda que estas tendências e políticas sejam constituídas por lógicas do passado e tenham gerado efeitos indesejados. A cidade transforma-se assim numa região cada vez mais próxima dos modelos urbanos globais com impactes locais, ainda longe de conseguir conciliar os tecidos com as políticas económicas, sociais e urbanísticas.

Como incentivo ao relançamento económico do país no pós-crise, foram aposta os sectores ligados às cidades e às suas dinâmicas urbanas, como são exemplo os sectores do turismo, reabilitação urbana, indústria cultural e criativa, educação superior, conhecimento, ciência e economia circular.

A evolução destes sectores foi alvo de reflexão, particularmente as suas interdependências e transformações. Reflexão esta que expôs a metamorfose transversal e complexa da metrópole de Lisboa, bem como o investimento e desinvestimento numa ampla panóplia de políticas públicas.

Depreendendo que as redes de colaboração e inovação da região não se encontram ainda amplamente consideradas e que apesar da atratividade de diversos agentes de inovação e investimento, para garantir a sua adequada inserção das redes globais de criação de valor, o autor afirma que a cidade terá de fortalecer "os seus elementos urbanos basilares: estabilidade democrática, a residencialidade, o bem-estar e a coesão social” (Seixas, 2021b, p. 101).

As divergências fase ao crescimento económico da AML e as disparidades internas são visíveis no documento Estratégia Regional de Lisboa. AML (CCDR-LVT \& AML, 2020), tanto nas trajectórias de "processo de coesão 
e convergência não virtuoso" (Seixas, 2021b, p. 102), como na "produtividade e inovação, coesão social e acesso aos bens urbanos" (Seixas, 2021b, p. 107).

Em contraciclo com as principais áreas metropolitanas europeias, a AML "mantém uma trajectória de crescente afastamento das restante regiões nacionais respectivas” (Seixas, 2021b, p. 102). As dinâmicas da AML são evidentemente assimétricas e a compreensão das razões destas assimetrias são elementos essenciais para explicar estas trajectórias e mitigar as disparidades. As explicações encontradas para tais assimetrias são os efeitos da crise financeira e das políticas de ajustamento, os desequilíbrios dos modelos de progresso e as debilidades do Estadoprovidência, bem como as fileiras pouco transacionais com o exterior da região e uma economia especializada e dependente de apoios públicos.

Para a mitigação destas disparidades, Seixas faz menção a múltiplos estudos na área da geografia económica, desenvolvidos por Paul Krugman (1953), Edward Glaeser (1967) e Michael Storper (n-?), que "confirmam que para uma economia urbana produtiva e resiliente é importante não apenas a concentração de muitas e pequenas empresas e instituições (...), mas também o fomento de interdependências entre outros agentes, sustentadas por dinâmicas activas de cooperação e promotoras de processos de inovação” (Seixas, 2021b, p. 105).

A questão da justiça espacial e das desigualdades sócio-económicas - assuntos da actualidade para as instituições e decisores políticos - é apresentada como princípios desenvolvidos pelas escolas de urbanismo do último século. Estes princípios refletem a temática de "fazer de cidade" de acesso universal para os diversos grupos e classes sociais, desde a habitação, às vias, infra-estruturas, espaços públicos, equipamentos e aos espaços comerciais e industriais.

$\mathrm{Na}$ continuidade das questões das desigualdades sócio-económicas e espaciais e dos desequilíbrios nas políticas urbanas, o sector da habitação mostra-se o mais afectado. Inúmeros estudos (Antunes, 2018; Agarez, 2018; IHRU, 2018; Silva et al. 2021), demonstram essas desigualdades. Também o estudo conduzido por Seixas e Antunes, publicado em 2019 num artigo intitulado "Housing Market Access in the Lisbon Metropolitan Area: Between the Financial and the Pandemic Crises" (Antunes \& Seixas, 2019), revela as estruturas de ocupação dos mercados de venda e arrendamento habitacional na AML, bem como as suas transformações entre 2010 e 2020.

Sobre as questões do arrendamento a "aproximação a padrões [globais de evolução das rendas urbanas] decorrerá em Lisboa de forma muito rápida ou mesmo vertiginosa. E não apenas sobre um vasto património edificado, (...) [mas também] sobre tecidos humanos e socioeconómicos que existem nos bairros centrais e semi-centrais" (Seixas, 2021b, p. 120), o que aproximará os valores das rendas nacionais aos valores internacionais e colocará muitos agregados familiares com dificuldades de acesso à habitação.

Relativamente à caracterização da habitação social e de renda apoiada - que é escassa - estes são na sua maioria bairros de grandes dimensões e densidade, onde apesar do trabalho de dotação de infra-estruturas, equipamentos e acção social e comunitária, a fraca qualidade urbanística e arquitectónica, o estigma e a segregação permanecem.

O Levantamento Nacional das Necessidades de Realojamento Habitacional, realizado pelo IHRU (2018), contactou cerca de 26 mil agregados familiares em situação de carência habitacional, metade deles na AML e particularmente nos municípios de Lisboa, Amadora, Almada e Loures. É de notar que este levantamento está desactualizado, face a novos dados enquadrados nos levantamentos realizados para as Estratégias Locais de Habitação que contabilizaram maior número de agregados familiares em carência habitacional e que denotaram também maiores vulnerabilidades no acesso habitacional nas classes médias e médias-baixas urbanas.

"Suceder-se-á uma autêntica revolução [física e social] no vasto e degradado património edificado de Lisboa histórica" (Seixas, 2021b, p. 122), sinónimo da denominada gentrificação, devido ao intenso processo de metamorfose de Lisboa estar intrinsecamente ligado às transformações dos investimentos imobiliários.

Outro desafio colocado para este século são as questões ecológicas, particularmente "as alterações climáticas, a perda de biodiversidade e o consumo não sustentável de recursos” (Seixas, 2021b, p. 127). Após o desenvolvimento de inúmeras assembleias, acordos e agendas, que foram sendo trabalhadas desde 2015 para a 
consciencialização e mitigação da problemática, surge o "Pacto Ecológico Europeu", que implicará profundas transformações na economia e na sociedade.

Para atingir a transição verde e sustentável, as cidades e a vida urbana assumem-se como lugares essenciais para a transformação, particularmente as estruturas de organização - espacial, social e económica - produção e consumo. Destacam-se as políticas ambientais - introduzidas em Portugal nos anos 80, através dos primeiros enquadramentos legais de ordenamento do território - e as medidas como os corredores verdes de Gonçalo Ribeiro Telles (1922-2020) - posteriormente inseridos no Plano Director Municipal de Lisboa de 2012, como marcos que mostram a evolução e o acolhimento das temáticas ecológicas. Outro marco foi em 2019 com a aprovação do Plano Metropolitano de Adaptação às Alterações Climáticas pelos dezoito municípios que compõe a AML.

No entanto, as mudanças aconteceram em todos os sectores e fileiras da região metropolitana de Lisboa e não somente no sector ambiental. Por esse motivo, é de salientar dentro das questões da transição ecológica, o sector dos transportes e da mobilidade, turismo e sistema alimentar - da produção à distribuição - como os maiores responsáveis pela estagnação e, simultaneamente, os que exigem políticas mais robustas, para alcançar a transição. Não obstante, as medidas e dinâmicas associadas com a regeneração ecológica serão igualmente relevantes para a alavancagem e transição sócio-económica e espacial da metrópole de Lisboa.

“A metrópole de Lisboa tem sido estruturada no sentido de uma configuração geográfica crescentemente complexa. Transformando-se de uma estrutura radial e quase exclusivamente polarizada na sua principal centralidade, para uma estrutura mais polinuclear e reticulada" (Seixas, 2021b, p. 134). Esta é a definição utilizada pelo autor para descrever o desenvolvimento da metrópole de Lisboa desde os anos 90. Mais recentemente esta metrópole, em constante metamorfose, tem sofrido um processo de construção de identidade e de reestruturação seja pela "crescente complexidade sociocultural, novos padrões de mobilidade e a tendencial configuração reticular da geografia urbana e regional” (Seixas, 2021b, p. 135), em linha com o conceito de pós-metrópole, desenvolvido por Edward Soja (1940-2015). O conceito identifica a pós-metrópole como "vastos sistemas hiper-urbanos, resultantes da cada vez mais complexa evolução das sociedades no espaço e no tempo" (Seixas, 2021b, p. 135), conceito que se aproxima da descrição mais recente da metrópole de Lisboa.

No contexto das profundas transformações e desenvolvimento urbano da pós-metrópole, as primeiras e segundas coroas de Lisboa beneficiaram da evolução do processo de metamorfose pós-metropolitana, através da atractividade de novos residentes e empresas, zonas que foram ao encontro da tão necessária regeneração e redinamização económica e social.

Simultaneamente os grandes projectos urbanos e intenções para o desenvolvimento da metrópole não foram tão bem-sucedidos, na sua premente regeneração urbana, devido à ainda distante realidade da "perspectiva de uma grande metrópole de duas margens, com o Estuário do Tejo como elemento focal em torno do qual se recentrariam actividades, humanidades e ecologias. (...) Entretanto, as margens ribeirinhas pós-industriais continuam a aguardar por significativos investimentos de regeneração. Nestes amplos espaços e em locais privilegiados (...) têm-se sucedido tentativas de renovação urbana através de grandes projectos, (...) em relativa mimetização da EXPO'98”' (Seixas, 2021b, pp. 143-144).

Paralelamente às questões urbanas, sociais e económicas, a política também é alvo de transformações. As políticas da cidade e da metrópole são por vezes "mais ousadas do que as delineadas pelos Estado e outras estruturas de governação" (Seixas, 2021b, p. 145). No caso da cidade e da metrópole de Lisboa, "tem-se assistido a um gradual processo de metamorfose nas dimensões políticas do sistemas urbano" (Seixas, 2021b, p. 146), nomeadamente nas instituições e movimentos sociais.

Esta metamorfose e evolução corrente da política urbana em Lisboa será, nas palavras de Seixas, decisiva para a evolução futura de toda a região. Matérias como a desterritorialização dos fluxos de capital e de informação, a progressiva exposição dos territórios a agentes e a externalidades de ordem global e a reformulação das estruturas administrativas das cidades - incluindo processos de descentralização e atribuição de competências e responsabilidades para o poder local - são factores essenciais a ter em conta nesta evolução. 
No âmbito do urbanismo e do ordenamento do território, novos modelos e políticas públicas são necessárias para colmatar os desfasamentos entre a teoria e a prática. É premente incluir no planeamento e na gestão urbana "temas mais transversais como a regeneração de habitats, o empreendedorismo económico, as intervenções sociocomunitárias e as questões ecológicas" (Seixas, 2021b, p. 147)

Paralelamente à geografia política e institucional, as questões da cidadania são outro factor que se tem transformado e evoluído. A cidadania apresenta agora maior dinamismo e ocupação do espaço publico e da política urbana, como se tem assistido recentemente em iniciativas da sociedade civil, movimentos sociais e intervenções cívicas na AML. Denota-se assim, um crescente envolvimento social nas questões urbanas e territoriais, relacionadas com as múltiplas dimensões do direito à cidade e uma exigência para a renovação dos sistemas políticos da AML.

\section{Entre extraordinárias possibilidades e exasperantes fragilidades: Projectar o Horizonte}

A última secção, intitulada 'Horizonte', aclara perspectivas e visões sobre a constante construção e metamorfose do território, bem como as tendências de "novas formas de habitar, trabalhar e de conviver nas cidades" (Seixas, 2021 b, p. 158). As profundas transformações da cidade, exacerbadas pelo actual contexto pandémico, alteraram profundamente a forma como experienciamos a vida urbana, expuseram as fragilidades, vulnerabilidades e desigualdades já instaladas na sequência de outras crises.

Sobre a questão da pandemia provocada pelo SARS-Cov-2, num ensaio sobre urbanismo para o jornal Público, intitulado "A cidade em Metamorfose", no âmbito do livro Lisboa em Metamorfose, Seixas afirma que "a resiliência, a capacidade de reacção e, no fundo, a coesão e a maturidade de um organismo, visto no seu todo, reconhecem-se bem nestas situações” (Seixas, 2021a).

O teletrabalho, os serviços digitais personalizados, as redes comunitárias, o consumo ecológico, a mobilidade suave e as relações entre o urbano e o rural, são tendências provenientes da crise pandémica. Estas tendências de transformação, desenvolverão gradualmente "novas formas de habitar, de trabalhar e de conviver nas cidades" (Seixas, 2021b, pp. 157-158).

Em tom de resposta às questões inicialmente colocadas, Seixas refere no livro que "após cinco décadas de explosão e pelo menos uma década de transição, Lisboa metamorfoseou-se muito, como um todo e nos seus mais diversos tecidos" e que "os múltiplos desafios que a região metropolitana de Lisboa tem pela frente - uma economia produtiva, social, redistributiva e circular; comunidades coesas e solidárias; habitats e mobilidades acessíveis, qualificados e ecológicos - são inevitavelmente interdependentes e subsidiários entre si.” (Seixas, 2021b, pp. 158 e 160).

Assim o autor expõe a premência em compreender esta metamorfose e os desafios a partir de três pontos essenciais, que contribuirão para o progresso fundamentalmente sócio-territorial da cidade: 1) A elevação do território como tema nobre da política, bem como a maturação dos instrumentos de Planeamento Urbano, de Ordenamento do território e de Planeamento Estratégico; 2) A gestão das heteronímias da cidade e o posicionamento da mesma face às questões de ordem global e especificidades da aplicação dessas mesmas questões globais, tal como foi princípio do Plano Director Municipal de Lisboa de 1994, a construção colectiva da cidade que pretendemos; 3) A requalificação urbana, particularmente nos bairros e nas comunidades mais vulneráveis, através da reversão das anteriores tendências de especialização das áreas centrais face às periféricas. Permite assim a criação de serviços de proximidade e de novas possibilidades de mistura funcional, tal como as propostas de modelos urbanos 'alternativos' - Ville du quart d'heure ou, em português, a Cidade dos 15 minutos - modelo em crescimento consistente noutras cidades europeias e em organismos, tais como o Conselho Europeu de Urbanistas ou a própria União Europeia. 


\section{A cidade como filha de um Deus menor: Perspectivas de desenvolvimento de novas investigações}

O livro de João Seixas oferece uma multiplicidade de discursos sobre os tecidos e as estruturas complexas que compõem as nossas cidades e metrópoles. É uma reflexão maturada sobre o crescimento da cidade, crítica sobre as explosões e transições a que a AML foi sujeita nas últimas seis décadas, bem como analítica das metamorfoses e incertezas dos tempos futuros.

Apesar do livro se dirigir para um público-alvo mais abrangente, até pela forma narrativa como está escrito, esta obra é inteiramente relevante para o contexto académico. Não obstante o determinismo urbanístico do livro e a perspectiva intrínseca dos fenómenos abordados, esta é uma obra que servirá de referência tanto para investigações sobre estudos urbanos, que identicamente contribuirão para a configuração das análises sobre as transformações dos espaços urbanos, como também para o desenvolvimento de políticas urbanas, de estruturas sociais e económicas em torno das temáticas urbanas, tal como instiga o autor no prefácio do livro ao "desenvolvimento de novas perspectivas, individuais e colectivas" (Seixas, 2021b, p. 10).

\section{Bibliografia}

Agarez, R. (Ed.) (2018). Habitação - Cem anos de políticas públicas em Portugal 1918-2018. Lisboa: Instituto da Habitação e da Reabilitação Urbana.

Antunes, G. (2018). Políticas de habitação: 200 anos. Lisboa: Caleidoscópio.

Antunes, G. \& Seixas, J. (2019). Housing Market Access in the Lisbon Metropolitan Area: Between the Financial and the Pandemic Crises, Critical Housing Analysis, pp. 58-72, https://doi.org/10.13060/23362839.2020.7.2.515

CCDR-LVT \& AML (2020). Estratégia Regional de Lisboa. AML. Publicação Digital. https://www.aml.pt/susProjects/susWebBackOffice/uploadFiles/wt1wwpgf_aml_sus_pt_site/componentText/SU S5F9C0ECCBA6EF/ESTRATEGIA_REGIONAL_DE_LISBOA_AML_LISBOA_2030.PDF

Drago, A. L. (2019). Um país a tornar-se urbano e democrático: A questão urbana na primeira década da democracia Portuguesa. [Tese de Doutoramento não publicada] Lisboa: Iscte - Instituto Universitário de Lisboa. Disponível em http://hdl.handle.net/10071/20495

Ferreira, V., Castro, A., Seixas, J., Silva, I. \& Lopes, E. (2002). Morfologias Urbanas e Espaços Públicos na Metrópole de Lisboa: Uma Aproximação Instrumental e Metodológica no Quadro de uma Investigação, CIDADES, Comunidades e Territórios, 5, pp. 81-97. https://revistas.rcaap.pt/cct/issue/view/584

IHRU (2018). Levantamento Nacional das Necessidades de Realojamento Habitacional. Lisboa: Instituto da Habitação e Reabilitação Urbana.

Nel·lo, O. (2015). La ciudad en movimiento: Crisis social y respuesta ciudadana. Madrid: Díaz \& Pons.

Palla, V. \& Martins, C. (1959). Lisboa: Cidade Triste e Alegre. Lisboa: ed. Autores. http://ag.fba.up.pt/textos/livro_lisboa.pdf

Pinto, T. \& Guerra, I. (2019). Housing policies, market and home ownership in Portugal: beyond the cultural model, CIDADES, Comunidades e Territórios, 39, pp. 101-114. https://revistas.rcaap.pt/cct/article/view/19019

Ribeiro, O. (1945). Portugal, o Mediterrâneo e o Atlântico. Coimbra: Coimbra editora, limitada. https://purl.pt/421 
Salgueiro, T. B. (1977). Bairros Clandestinos da periferia de Lisboa, Finisterra-Revista Portuguesa de Geografia 12 (23), pp. 28-55.

Salgueiro, T. B. (1997). Lisboa: metrópole policêntrica e fragmentada, Finisterra - Revista Portuguesa de Geografia, XXXII (63), pp. 179-190.

Seixas, J. (2013). A Cidade na Encruzilhada. Repensar a Cidade e a Sua Política. Porto: Afrontamento

Seixas, J. (2021a). A Cidade em Metamorfose, Jornal Público. 12 de Junho de 2020. https://www.publico.pt/2020/06/12/local/noticia/cidade-metamorfose-1920202

Seixas, J. (2021b). Lisboa em Metamorfose. Lisboa: Fundação Francisco Manuel dos Santos

Seixas, J. (Coord.) (2018). Projecções de Lisboa: Utopias e estratégias para uma cidade em movimento perpétuo. Lisboa: Caleidoscópio e CML.

Silva, M., Baptista, L., Ribeiro, F., Felizes, J. \& Vasconcelos, A. (Coord) (2021). Espaço Urbano e Habitação básica como primeiro direito. Lisboa: Humus 